\title{
Perceptions regarding cardiothoracic surgical training at Veterans Affairs hospitals
}

\author{
Faisal G. Bakaeen, MD, ${ }^{\mathrm{a}, \mathrm{b}, \mathrm{c}}$ Elizabeth H. Stephens, PhD, ${ }^{\mathrm{a}}$ Danny Chu, MD, ${ }^{\mathrm{a}, \mathrm{b}}$ William L. Holman, MD, ${ }^{\mathrm{d}}$ \\ Ara A. Vaporciyan, MD, ${ }^{e}$ Walter H. Merrill, MD, ${ }^{f}$ and Frederick L. Grover, MD $^{\mathrm{g}}$
}

Objective: With cardiothoracic education going through a critical phase of reevaluation and adaptation, we investigated perceptions of Veterans Affairs hospitals in cardiothoracic training.

\begin{abstract}
Methods: A content-validated survey was distributed electronically to 676 cardiothoracic surgery residents, recent cardiothoracic graduates (on or after June 2006), cardiothoracic surgery chairpersons, program directors, associate program directors, and section heads. The Cardiothoracic Surgery Network was used to identify target recipients and their e-mail addresses.
\end{abstract}

\begin{abstract}
Results: Forty-three percent of the target recipients (292/676) completed the survey. Of those who were residents, 59\% (65/111) rotated at a Veterans Affairs hospital during their cardiothoracic training; this rotation accounted for $25 \%$ or more of the total training period for $19 \%$ of them (21/111). A Veterans Affairs appointment was held by $42 \%$ of program directors/chairpersons (20/48) and $24 \%$ of graduates, associate program directors, and section heads (31/129). An affiliation with a Veterans Affairs hospital was rated as somewhat to very beneficial by $93 \%$ of the responders (273/292), and the cardiothoracic training received at Veterans Affairs facilities was rated as good to excellent by $73 \%$ of the responders (213/292). Sixty-nine percent of respondents (201/292) reported the operating room environment at Veterans Affairs hospitals to be at least as conducive to learning as that at the affiliate teaching hospital, and 76\% (223/292) indicated that residents get more autonomy and handson experience at Veterans Affairs institutions. In addition, 64\% of responders (188/292) reported that they would seek or recommend a Veterans Affairs job. Responses were positive toward the Veterans Affairs system regardless of whether the responder had any Veterans Affairs affiliation (ie, appointment as staff or rotation as resident); however, a Veterans Affairs affiliation was associated with a higher rate of positive responses regarding Veterans Affairs hospitals.
\end{abstract}

Conclusions: These findings suggest that Veterans Affairs hospitals are perceived as providing valuable experience in cardiothoracic training. The results warrant additional studies to further define the educational role of Veterans Affairs hospitals and help shape existing and future collaboration between cardiothoracic residency programs and the Veterans Affairs. (J Thorac Cardiovasc Surg 2011;141:1107-13)

The specialty of cardiothoracic surgery is going through a critical phase of reevaluation and adaptation. ${ }^{1-3}$ Several residency positions in the United States are unfilled or unmatched, and current projections show that the demand for cardiothoracic surgeons will soon exceed the supply

\footnotetext{
From the Division of Cardiothoracic Surgery, ${ }^{a}$ Michael E. DeBakey Department of Surgery, Baylor College of Medicine and The Michael E. DeBakey Veterans Affairs Medical Center, Houston, Tex; Division of Cardiovascular Surgery, ${ }^{\mathrm{b}}$ The Texas Heart Institute at St Luke's Episcopal Hospital, Houston, Tex; Academy of Distinguished Educators, ${ }^{\mathrm{c}}$ Baylor College of Medicine, Houston, Tex; Division of Cardiothoracic Surgery, ${ }^{\mathrm{d}}$ University of Alabama, Birmingham, Ala; Department of Thoracic Surgery, ${ }^{\mathrm{e}}$ University of Texas MD Anderson Cancer Center, Houston, Tex; Department of Cardiothoracic Surgery, ${ }^{\mathrm{f}}$ University of Mississippi, Jackson, Miss; and Department of Surgery, ${ }^{\mathrm{g}}$ The University of Colorado Denver, Aurora, Colo.

Disclosures: Authors have nothing to disclose with regard to commercial support. Received for publication Nov 2, 2010; revisions received Dec 20, 2010; accepted for publication Jan 24, 2011.

Address for reprints: Faisal G. Bakaeen, MD, FACS, Department of Cardiothoracic Surgery, Michael E. DeBakey VAMC, OCL 112, 2002 Holcombe Blvd. Houston, TX 77030 (E-mail: fbakaeen@bcm.edu).

$0022-5223 / \$ 36.00$

Copyright (c) 2011 by The American Association for Thoracic Surgery doi:10.1016/j.jtcvs.2011.01.043
}

and that there will probably be a shortage of cardiothoracic surgeons in the near future. ${ }^{4}$ Therefore, the imperative to train, retain, and graduate competent and skillful cardiothoracic surgeons is stronger than it has ever been, but there are tough obstacles to overcome.

Decreasing reimbursement, the implementation of the 80-hour work week, administrative bureaucracy and pressures, public reporting of outcomes, and the reduced availability of research funding have made the academic mission much harder for surgeons across the board. ${ }^{5,6}$ Because of the onslaught of disruptive technologies and patients' increasing preference for less invasive procedures, there are now many cardiothoracic interventions that faculty members must themselves study and practice before they can teach these procedures to residents. In addition, older and sicker patients are being referred for cardiothoracic surgery, adding to the risks associated with the procedures and diminishing the pool of the more straightforward cases that are typically designated as "teaching cases."

Currently, $86 \%$ of US medical schools are formally affiliated with Veterans Affairs (VA) hospitals, and the 
Department of Veterans Affairs funds approximately $10 \%$ of all US residency-training positions. ${ }^{7}$ The VA offers diverse clinical and research opportunities, an advantage that is reflected in a survey by Robinson and colleagues, ${ }^{8}$ in which $91 \%$ of surgical chairs stated that a VA affiliation was important in general surgery residency training. Many of the VA cardiothoracic surgery centers have cardiothoracic residents from affiliate institutions who rotate at the VA as part of their training. ${ }^{9}$

Nonetheless, little is known about the quality of cardiothoracic training and education received at VA facilities. Therefore, we conducted a targeted nationwide survey to assess perceptions regarding cardiothoracic training at VA hospitals.

\section{PATIENTS AND METHODS \\ Study Design and Target Population}

Small focus groups of cardiothoracic residents and program directors helped us identify relevant items pertaining to cardiothoracic training and VA hospitals. Next, we designed a 13-item survey that incorporated the most important items and that was as simple and brief as possible. The survey was evaluated and refined by leading figures in cardiothoracic education. Next, the survey and associated study methods were reviewed by our center's institutional review board, and an exemption was granted.

Our target population consisted of current cardiothoracic residents (excluding those who started after July 2010), residents who graduated in or after 2006, program directors, associate directors, departmental chairpersons, and section heads. The Cardiothoracic Surgery Network (CTSNet) ${ }^{10}$ and the Accreditation Council for Graduate Medical Education ${ }^{11}$ websites were used to identify target subjects. All e-mail listings and other information extracted were publicly available. The cutoff graduation year of 2006 for inclusion in the survey was used because the CTSNet's listing of residents was most consistent and complete for residents who graduated in or after 2006. In addition, we thought that recent graduates are not far removed from residency and that their feedback is likely to be up-to-date and relevant to this study. In preparing the final e-mail list, we excluded surgeons with invalid or unlisted e-mail addresses, and we used training information from the web pages of individual surgeons to exclude those who were not enrolled or had not been enrolled in an accredited cardiothoracic residency program in the United States.

The final survey instrument was distributed electronically between June 25 and July 7, 2010. Two rounds of e-mails, separated by at least 10 days, were sent to each subject; the first round was sent on a weekend, and the second round was sent on a weekday (excluding Mondays). The e-mails contained an invitation to participate in the survey and an electronic link to access the survey. The e-mail clearly stated that participation in the survey was voluntary and anonymous. Accessing and completing the survey were considered to constitute implicit consent to participate. The option of replying "no" to the e-mail was available for recipients who had no experience with the VA or did not feel qualified to take the survey. Responses were collected through August 7, 2010.

\section{Items Incorporated Into the Survey and Statistical Analyses}

The survey queried demographic data, professional rank, staff affiliation status with the VA, residency program affiliation with the VA, and duration of residency training at the VA. The survey evaluated perceptions of the VA regarding the value of and satisfaction with training, autonomy granted to residents by staff, learning environment, and operating room equipment. Also, the subjects were asked whether they would consider a VA job and whether they would recommend one to others. The survey concluded by encouraging responders to express any further opinions regarding the VA and cardiothoracic education in a comment section.

Most analyses were descriptive. The chi-square test was used to compare answers from respondents affiliated and not affiliated with the VA.

\section{RESULTS \\ Recipients of Survey and Response Rate}

A total of 747 subjects who satisfied our inclusion criteria were listed on CTSNet, but 71 of the residents and recent graduates had invalid or missing e-mail addresses, or their cardiothoracic training at an accredited US program could not be verified. Therefore, 676 subjects formed our denominator for calculating the response rate (Figure 1).

The total response rate was $54 \%$ (367/676), but 75 subjects chose to opt out of the survey because they had no experience with VA hospitals and felt unqualified to complete the survey. Therefore, our final data set comprised the responses of the $43 \%$ of subjects (292/676) who completed the survey.

\section{Demographics}

Of the respondents, approximately $60 \%(175 / 292)$ were aged 30 to 39 years, $32 \%$ (92/292) were aged 40 to 59 years, $7 \%(21 / 292)$ were aged 60 years or more, and $1 \%(4 / 292)$ were aged less than 30 years. Women accounted for $9 \%$ of respondents (25/292) and $13 \%$ of the current residents (14/ 111), which matches data previously published by the American Medical Association. ${ }^{12}$

\section{Affiliation With the Veterans Affairs}

As part of their cardiothoracic training, 59\% of the residents $(65 / 111)$ rotated at a VA hospital; the VA rotation accounted for $25 \%$ or more of the total training period for $19 \%(21 / 111)$ of them. A VA appointment was held by $42 \%$ of the program directors/chairpersons (20/48) and by $24 \%$ of graduates, associate program directors, and section heads (31/129) (Table 1).

\section{Perceptions of Cardiothoracic Training at Veterans Affairs Hospitals}

An affiliation with a VA hospital was reported to be somewhat to very beneficial by $93 \%$ of the responders $(273 / 292)$, and the cardiothoracic training received at the VA was rated as good to excellent by $73 \%$ of the responders (213/292) (Figure 2). Sixty-nine percent of respondents (201/292) reported the operating room environment at the VA to be at least as conducive to learning as that at the affiliate teaching hospital, and 76\% (223/292) indicated that residents get more autonomy and hands-on experience at the VA than at other institutions. In addition, $64 \%$ of responders (188/292) reported that they would seek or recommend a VA job. 


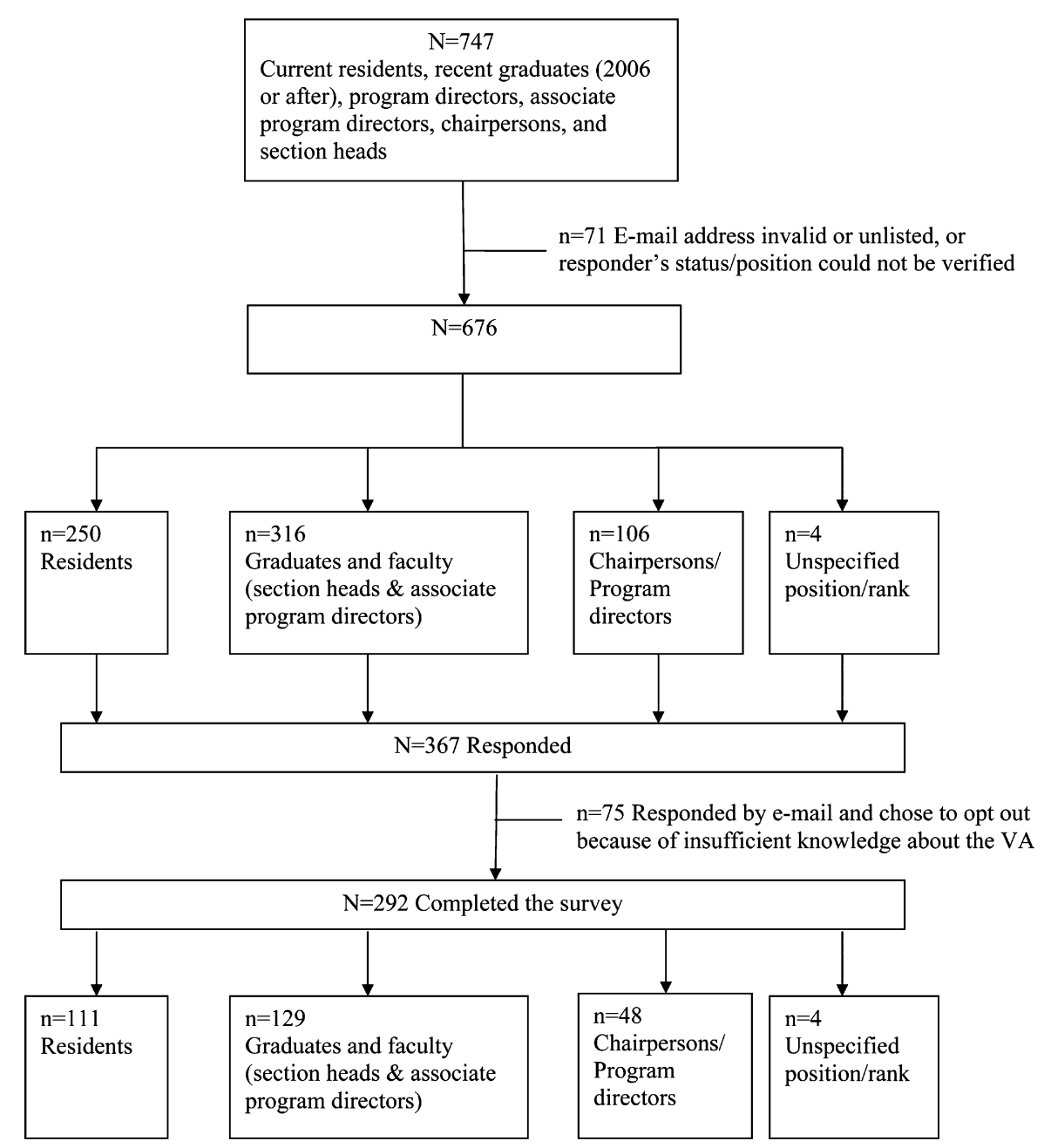

FIGURE 1. Survey recipients and responders. VA, Veterans Affairs.

\section{Veterans Affairs Affiliation Versus No Veterans Affairs Affiliation}

The responses were positive toward the VA regardless of the responder's affiliation (VA appointment vs no VA appointment as staff, and VA rotation vs no VA rotation as resident). However, a VA affiliation was associated with a higher rate of positive responses regarding the VA (Figure 3).

\section{Free-Form Comments}

Twenty-two percent of respondents (65/292) made additional comments. The tone of those comments was mixed and ranged from favorable $(\mathrm{n}=35)$ to critical $(\mathrm{n}=21)$ toward the VA; the remaining comments $(n=9)$ were deemed neutral. The critical comments were mainly related to lower case loads, less efficiency, administrative hurdles, and a lack of staffing and support, especially outside of routine hours.

\section{DISCUSSION}

From its inception, the VA has had a unique association with cardiothoracic surgery. Dr DeBakey's efforts with the federal government were crucial in the establishment of the Department of Veterans Affairs hospitals and the mobile army surgical hospital, both truly remarkable and enduring models of health care delivery. ${ }^{13}$ It was at the VA

TABLE 1. Veterans Affairs affiliations of respondents $(N=292)$

\begin{tabular}{lc}
\hline & $\mathbf{n}(\%)$ \\
\hline Chairperson, program director $(\mathrm{n}=48)$ & \\
$\quad$ with a VA appointment & $20(42)$ \\
$\quad$ without a VA appointment & $28(58)$ \\
Graduate, associate program director, section head $(\mathrm{n}=129)$ & \\
$\quad$ with a VA appointment & $31(24)$ \\
$\quad$ without a VA appointment & $98(76)$ \\
Cardiothoracic resident $(\mathrm{n}=111)$ & \\
$\quad$ rotating at VA & $65(59)$ \\
percentage of cardiothoracic training received at VA & \\
$1 \%-24 \%$ & $45(41)$ \\
$25 \%-50 \%$ & $18(16)$ \\
$>50 \%$ & $2(2)$ \\
not rotating at VA & $46(41)$ \\
\hline$V A$, Veterans Affairs.
\end{tabular}




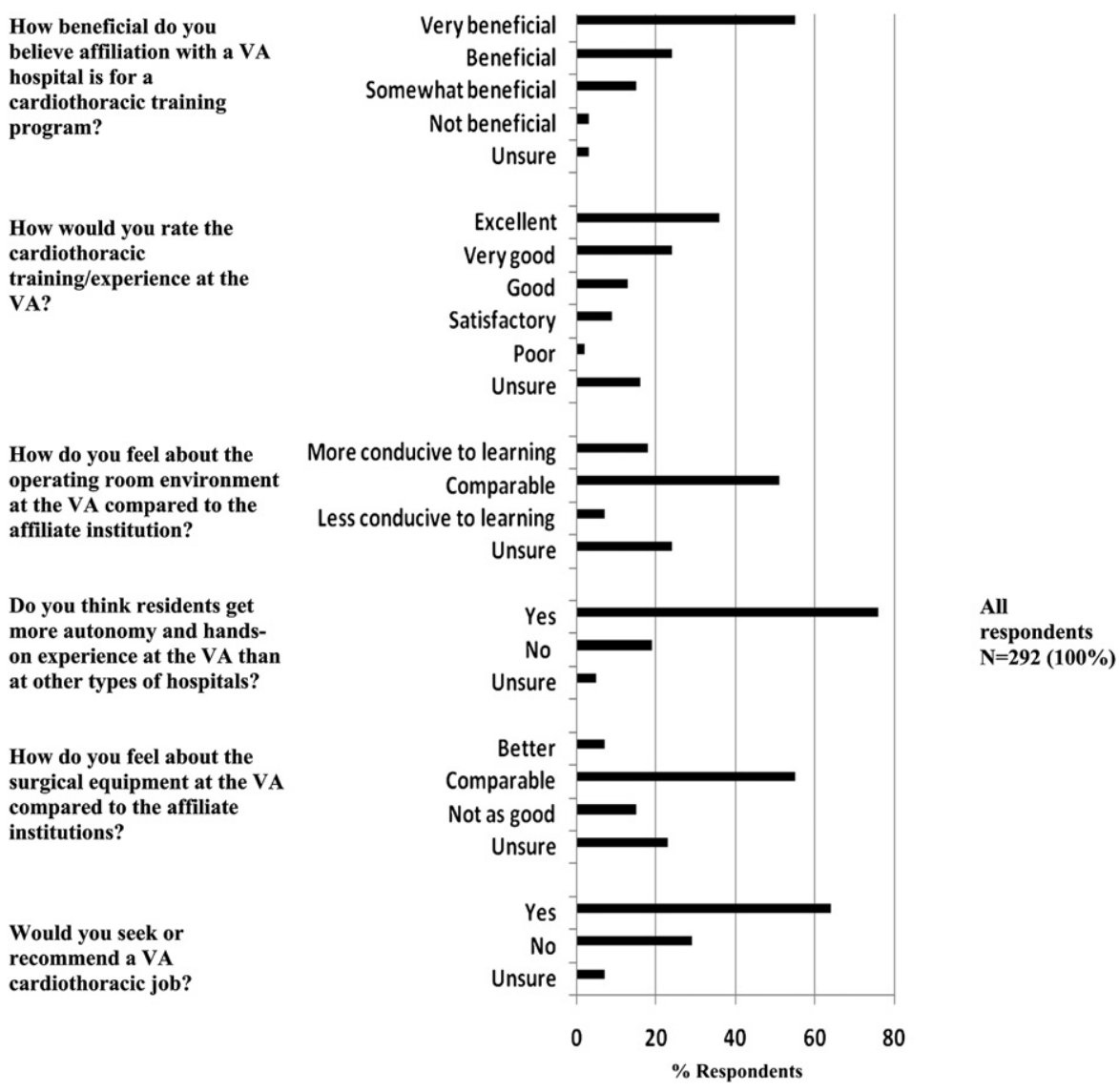

FIGURE 2. Perceptions regarding cardiothoracic training at VA hospitals.

hospital in Houston, later his namesake, that Dr DeBakey performed many of the early cardiothoracic procedures that he helped pioneer and teach to the next generation of cardiothoracic surgeons.
In a deliberate effort by the Department of Veterans Affairs, VA hospitals were moved to sites near medical schools. ${ }^{14}$ This was a major catalyst in establishing affiliations with academic medical centers and helped recruit

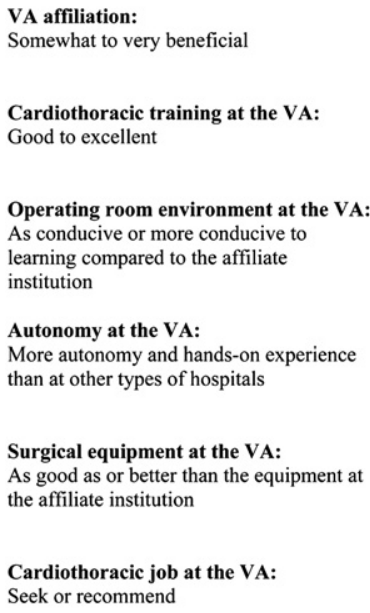

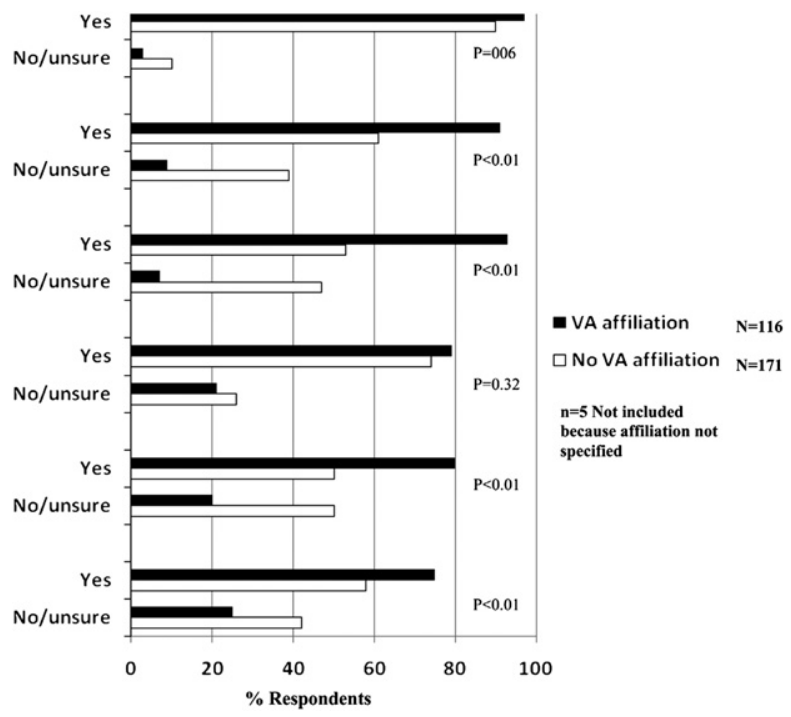

FIGURE 3. Differences in the perceptions of respondents with or without a VA affiliation regarding cardiothoracic training at VA hospitals. 
academic faculty at the VA. In our survey, $42 \%$ of cardiothoracic program directors and chairpersons had a VA appointment, and $59 \%$ of the residents rotated at the VA as part of their training. This mirrors the general medical community, in which $50 \%$ of practicing physicians have received a portion of their medical training at a VA medical center. $^{15}$

More than half of the 22 million surviving veterans are aged more than 60 years. ${ }^{16}$ The predominately older and male VA population, with its high prevalence of hyperlipidemia, hypertension, diabetes, and cigarette smoking, represents a highly susceptible population for cardiothoracic disease. The opportunity to care for this unique population can enrich the experience of cardiothoracic residents. The majority of the survey respondents stated that a VA affiliation was beneficial and rated the training and experience they had at the VA as good to excellent (Figure 2). Many respondents made comments that expressed their appreciation of veterans, describing them as "unique" and "wonderful" patients whom the respondents cherished the opportunity to care for.

From a faculty standpoint, in this era of intense public scrutiny, there is tremendous pressure to achieve superior outcomes. In addition, hospital administrators and payers are constantly demanding greater efficiency and reductions in cost. The overriding temptation may be for faculty members to forgo the educational commitment and to focus on the everyday business aspect of surgery. This business model of health care delivery is perhaps more manifest at academic and private hospitals than at government facilities such as the VA. In the VA system, the patient population and system of referrals are fixed, so there is less competition than in non-government healthcare systems. Therefore, the VA may provide a more protected and relaxed environment than other hospitals when it comes to teaching residents. This thesis is supported by our survey results; many responders indicated that the learning environment in VA operating rooms is conducive to learning and that residents get more autonomy and hands-on experience in the operating room at the VA than at the affiliate institution.

In the field of cardiothoracic surgery, hands-on experience is critical for trainees as they follow the steep learning curve this discipline requires. Although the volume of isolated coronary artery bypass grafting (CABG) procedures is decreasing at the VA hospitals, just as it is nationally, isolated CABG has accounted for approximately $70 \%$ of cardiac cases performed in the VA system in recent years. ${ }^{9}$ This provides fertile ground for teaching residents and having them actually operate because many regard $\mathrm{CABG}$ as the quintessential cardiac "teaching case." Although they vary among VA hospitals, in general, the case mix and complexity of cardiac cases at the VA seem better suited for training residents than the highly specialized cases that are predominant at some university hospitals.

Our survey did not incorporate questions relating to the actual training experience of residents, including the case load and the actual percentage of cases performed by residents. Other published studies help shed some light on this area. For example, in the VA Randomized On/Off Bypass trial, residents were the primary surgeons in $55 \%$ and $64 \%$ of off-pump and on-pump cases, respectively. ${ }^{17}$ The VA Randomized On/Off Bypass investigators reported excellent patient outcomes, including high graft patency rates, regardless of whether the primary surgeon was a resident or staff member. In a recent retrospective review from a large VA center, residents performed CABG as primary surgeons (performing at least $50 \%$ of the distal anastomoses) in more than $95 \%$ of CABG cases. ${ }^{18}$ Risk-adjusted outcomes were similar for cases performed by staff versus residents. These findings are reassuring and similar to those of a multicenter VA study on aortic valve replacement in which residents were the primary surgeons for approximately $50 \%$ of the cases. $^{19}$

The American Board of Thoracic Surgery recently proposed that a "comprehensive, integrated cardiothoracic training beginning after medical school graduation [become] the sole pathway leading to ABTS certification beginning in 2020" - a major change that might help draw applicants toward cardiothoracic surgery earlier in their careers. ${ }^{20}$ The integrated cardiothoracic surgery program means that in the near future, cardiothoracic faculty will be dealing with residents, including interns with little to no surgical experience. The positive perceptions expressed in this survey regarding the educational experience and learning environment at the VA suggest that the VA can be good place for early exposure to cardiothoracic surgery. A positive experience at the VA may help affiliate institutions to retain residents and better prepare them for more challenging rotations. At the other end of the spectrum, chief residents may benefit from the greater degree of autonomy and hands-on experience available at the VA.

The VA has made tracking of surgical outcomes one of its priorities, and the VA's Continuous Improvement in Cardiac Surgery Program was implemented to monitor cardiac surgery outcomes. ${ }^{21}$ Some of the respondents in the present study speculated that the focus on published observedto-expected mortality ratios may have harmed resident training by making both VA and non-VA surgeons more selective of operative cases and diminishing their enthusiasm for letting residents operate.

The majority of the respondents indicated that they would seek or recommend a VA job. This may be because the VA provides a group practice model that allows for the development of clinical expertise and provides protected time for research interests. The VA also offers career development awards, basic research and merit review 
programs, and health service research. ${ }^{22,23}$ In addition, the VA Cooperative Studies Program has supported several large, multi-institutional clinical trials, including cardiac surgery trials. ${ }^{17,24}$

Many of the free-form comments made by the respondents were favorable regarding cardiac surgery training and the health care system at the VA, but some comments were critical. Whereas some respondents described the workload at the VA as "manageable," conducive to teaching, and contributive to a balanced lifestyle for residents and staff, others described the VA as "inefficient" and reported that they performed fewer cases at the VA than they needed for effective training. Some respondents pointed out that out-of-hours care and emergency surgery were more challenging to conduct at the VA, citing suboptimal support by ancillary staff as a major limitation. The split in opinions about the quality of equipment at the VA compared with the affiliate institution (Figure 3) was also reflected in the respondents' free-form comments. Some respondents expressed their frustration with the excessive "paperwork" and "bureaucracy" in the VA system.

\section{Study Limitations}

There are several limitations to this study. The evaluable response rate $(43 \%)$, although higher than that of many other educational surveys, ${ }^{25}$ is still low enough to threaten the validity of the study. Therefore, we may not be able to generalize the results to all cardiothoracic surgery programs or VA hospitals. In addition, although most of the 42 VA hospitals that perform cardiothoracic surgery have a medical school affiliation, not all of them have cardiothoracic residents, and many cardiothoracic surgery programs have no VA affiliation. Furthermore, although we tried to reduce the number of uninformed responses by allowing subjects to opt out of the survey if they had no experience relating to the VA, this measure probably did not eliminate uninformed responses entirely. It is interesting that more than half of the respondents had no VA affiliation and that the responses were consistently in favor of the VA regardless of the respondent's affiliation (Figure 3).

An additional limitation common to all surveys is convenience sampling and the biases associated with it. Subjects who chose to respond to our survey may have been more enthusiastic about cardiothoracic education than nonrespondents, or they may have had perceptions about the VA that are not shared by the whole population that we intended to target. Our survey did not distinguish between the cardiac and thoracic training tracks and the differential impact of the VA rotation on both. Finally, our study was designed to evaluate subjective perceptions regarding the role of the VA in cardiothoracic training and did not incorporate objective training metrics, such as the actual number of cases performed by residents at VA hospitals, or compare the level of involvement of residents in cases (eg, as primary surgeon vs assistant) at VA versus university hospitals. Despite these limitations, the survey's results suggest that cardiothoracic residents generally have a positive experience in VA hospitals. These findings should be of interest to program directors in cardiothoracic surgery.

\section{CONCLUSIONS}

The responses to the survey suggest that VA hospitals can provide a good training environment and that rotating at the VA is frequently perceived as beneficial. The results encourage further analysis of the role of the VA in cardiothoracic training and education. Such information can help shape existing and future collaboration between cardiothoracic residency programs and the VA system to better overcome the challenges facing our specialty.

Stephen N. Palmer, PhD, ELS, contributed to editing the article.

\section{References}

1. Verrier ED. Who moved my heart? Adaptive responses to disruptive challenges. J Thorac Cardiovasc Surg. 2004;127:1235-44.

2. Cohn LH. The times they are a-changin'. J Thorac Cardiovasc Surg. 2010;140: 3-4.

3. Fullerton DA. An endangered species. J Thorac Cardiovasc Surg. 2010;139: 4-12.

4. Williams TE Jr, Sun B, Ross P Jr, Thomas AM. A formidable task: population analysis predicts a deficit of 2000 cardiothoracic surgeons by 2030. J Thorac Cardiovasc Surg. 2010;139:835-41

5. Cobb JP, Warner BW. Challenges and a new vision for academic surgery. J Am Coll Surg. 2005;200:605-6.

6. Suliburk JW, Kao LS, Kozar RA, Mercer DW. Training future surgical scientists: realities and recommendations. Ann Surg. 2008;247:741-9.

7. Longo WE, Cheadle W, Fink A, et al. The role of the Veterans Affairs Medical Centers in patient care, surgical education, research and faculty development. Am J Surg. 2005;190:662-75.

8. Robinson C, Freischlag J, Brunicardi FC, Berger DH. The VA is critical to academic development. Am J Surg. 2010;200:628-31.

9. Bakaeen FG, Huh J, LeMaire SA, et al. The July effect: impact of the beginning of the academic cycle on cardiac surgical outcomes in a cohort of 70,616 patients. Ann Thorac Surg. 2009;88:70-5

10. CTSNet: The Cardiothoracic Surgery Network. North American cardiothoracic residency programs. Available at http://www.ctsnet.org/cfapps/programs/. Accessed October 25, 2010.

11. Accreditation Council for Graduate Medical Education (ACGME). List of ACGME accredited programs and sponsoring institutions. Available at http:// www.acgme.org/adspublic/. Accessed October 25, 2010.

12. Brotherton SE, Etzel SI. Graduate medical education, 2008-2009. JAMA. 2009; 302:1357-72.

13. Michael DeBakey. Available at http://www.britannica.com/EBchecked/topic/ 154693/Michael-DeBakey. Accessed October 25, 2010.

14. Rege RV. Why should the VA continue academic affiliations? Am J Surg. 2004; 188:453-8

15. Gronvall JA. The VA's affiliation with academic medicine: an emergency postwar strategy becomes a permanent partnership. Acad Med. 1989;64:61-6.

16. United States Department of Veterans Affairs. Demographics: veteran population 2007. Available at http://www1.va.gov/VETDATA/Demographics/Demographics. asp. Accessed October 25, 2010.

17. Shroyer AL, Grover FL, Hattler B, et al. On-pump versus off-pump coronaryartery bypass surgery. $N$ Engl J Med. 2009;361:1827-37.

18. Bakaeen FG, Dhaliwal AS, Chu D, et al. Does the level of experience of residents affect outcomes of coronary artery bypass surgery? Ann Thorac Surg. 2009;87: 1127-34

19. Sethi GK, Hammermeister KE, Oprian C, Henderson W. Impact of resident training on postoperative morbidity in patients undergoing single valve replacement. Department of Veterans Affairs Cooperative Study on Valvular Heart Disease. J Thorac Cardiovasc Surg. 1991;101:1053-9. 
20. American Board of Thoracic Surgery. Available at http://www.tsda.org/docu ments/PDF/TSDA\%20Meetings/General\%20Sessions\%202009/ABTS_I-6_Com parison.Feins.5.09.pdf. Accessed October 25, 2010.

21. Grover FL, Shroyer AL, Hammermeister K, et al. A decade's experience with quality improvement in cardiac surgery using the Veterans Affairs and Society of Thoracic Surgeons national databases. Ann Surg. 2001;234:464-74.

22. Zucker S, Crabbe JC, Cooper Gt, et al. Veterans Administration support for medical research: opinions of the endangered species of physician-scientists. FASEB J. 2004;18:1481-6.
23. Cheadle WG. The Veterans Affairs research program: scientific and clinica excellence relevant to veterans' healthcare needs. Am J Surg. 2005;190: 655-61.

24. Passamani E, Davis KB, Gillespie MJ, Killip T. A randomized trial of coronary artery bypass surgery: survival of patients with a low ejection fraction. $N$ Engl $J$ Med. 1985;312:1665-71.

25. Vaporciyan AA, Reed CE, Erikson C, et al. Factors affecting interest in cardiothoracic surgery: survey of North American general surgery residents. $J$ Thorac Cardiovasc Surg. 2009;137:1054-62. 